\title{
Surgical Resection for Lymph Node Metastasis After Liver Transplantation for Hepatocellular Carcinoma
}

\author{
TORU IKEGAMI, TOMOHARU YOSHIZUMI, JYUNJI KAWASAKI, AKIHISA NAGATSU, \\ HIDEAKI UCHIYAMA, NOBORU HARADA, NORIFUMI HARIMOTO, SHINJI ITOH, \\ TAKASHI MOTOMURA, YUJI SOEJIMA and YOSHIHIKO MAEHARA
}

Department of Surgery and Science, Graduate School of Medical Sciences, Kyushu University, Fukuoka, Japan

\begin{abstract}
Background: Treatment strategies for lymph node (LN) metastasis after liver transplantation (LT) for hepatocellular carcinoma (HCC) have not been studied. Patients and Methods: The treatment modes and outcomes in patients with $L N$ metastasis after $L T(n=6)$ for $H C C$ were reviewed. Results: The mean time from $L T$ to $L N$ recurrence was 2.0 \pm 1.3 years, and the locations of the LNs recurrences included the phrenic $(n=2)$, common hepatic artery $(n=2)$, inferior vena cava $(n=1)$ and gastric $(n=1)$ regions. Treatments included surgery alone $(n=3)$, surgery followed by chemoradiation $(n=1)$, radiation followed by chemotherapy $(n=1)$, and chemotherapy, radiation and sorafenib $(n=1)$. Although the patients receiving nonsurgical treatments $(n=3)$ died within 1.2 years, those who underwent surgical removal of the metastatic LNs survived 11.2 years, 4.5 years and 0.8 years, respectively, without any signs of re-recurrence. Conclusion: Surgical resection is the only feasible and potentially curative treatment for $L N$ metastasis after LT for HCC.
\end{abstract}

Liver transplantation (LT) has become one of the treatments of choice for hepatocellular carcinoma (HCC), with an acceptable long-term survival rate in patients other than those with very advanced disease (1). However, HCC recurrence after LT remains a problem, occurring in up to $10-20 \%$ of transplanted patients and resulting in drastically decreased survival after recurrence $(1,2)$. Strategies to treat such recurrences after LT have not been studied in detail, in contrast to the extensive research that has been performed on possible predictors for post-LT HCC recurrence $(1,2)$.

Correspondence to: Toru Ikegami, MD, Department of Surgery and Science, Graduate School of Medical Sciences, Kyushu University, Fukuoka 812-8582, Japan. Tel: +81 926425466, Fax: +81 926425482, e-mail: tikesurg@ $\operatorname{surg} 2 . m e d . k y u s h u-u . a c . j p$

Key Words: Living donor liver transplantation, hepatocellular carcinoma, treatment for recurrence, lymph node metastasis.
A few reports have recently shown that surgical resection might be a more effective treatment option than other nonsurgical treatments, including chemotherapy $(2,3)$. However, these studies focused on metastasis to the lung, liver allograft, abdominal cavity or bone; few have addressed the feasibility of surgical management of lymph-node (LN) metastasis $(2,3)$. Therefore, we herein present the treatments and outcomes of six patients who developed LN metastasis of HCC after LT.

\section{Patients and Methods}

In total, 211 living donor LTs (LDLTs) for HCC were performed at Kyushu University Hospital beginning in October 1996 after approval from the Ethics and Indications Committee of Kyushu University. The selection criteria for LDLT for HCC excluded apparent macroscopic vascular invasion, extrahepatic metastasis, and a tumor size of $>5 \mathrm{~cm}$ with a des-gamma carboxyprothrombin concentration of $>300$ $\mathrm{mAU} / \mathrm{ml}$. The LDLT procedures for donor and recipients, perioperative care, and immunosuppression regimen were performed as previously reported (3). No adjuvant chemotherapy was performed.

The routine clinical follow-up of the patients receiving LDLT for HCC included measurement of tumor markers (des-gamma carboxyprothrombin and alpha-fetoprotein) every 3 months and a thoracoabdominal-pelvis computed tomography scan every 6 months. Fluorodeoxyglucose-positron-emission tomography and bone scintigraphy were performed if an increase in the tumor marker concentrations was noted.

\section{Results}

Among the patients who underwent LDLT for HCC $(\mathrm{n}=212)$, 28 patients showed recurrent HCC in the lung ( $n=9)$, LNs $(\mathrm{n}=6)$, bone $(\mathrm{n}=5)$, liver $(\mathrm{n}=4)$, peritoneum $(\mathrm{n}=3)$ and adrenal gland $(n=1)$. The mean period from LDLT to recurrence was $1.7 \pm 1.3$ years. The 5- and 10-year cumulative patient survival rates were $89.3 \%$ and $85.5 \%$ in those without recurrence $(\mathrm{n}=184)$ and $38.8 \%$ and $30.7 \%$ in those with recurrence, respectively $(p<0.01)$.

Six patients (three male, three female, average age $=58.5 \pm 5.1$ years) presented with recurrent disease in the 

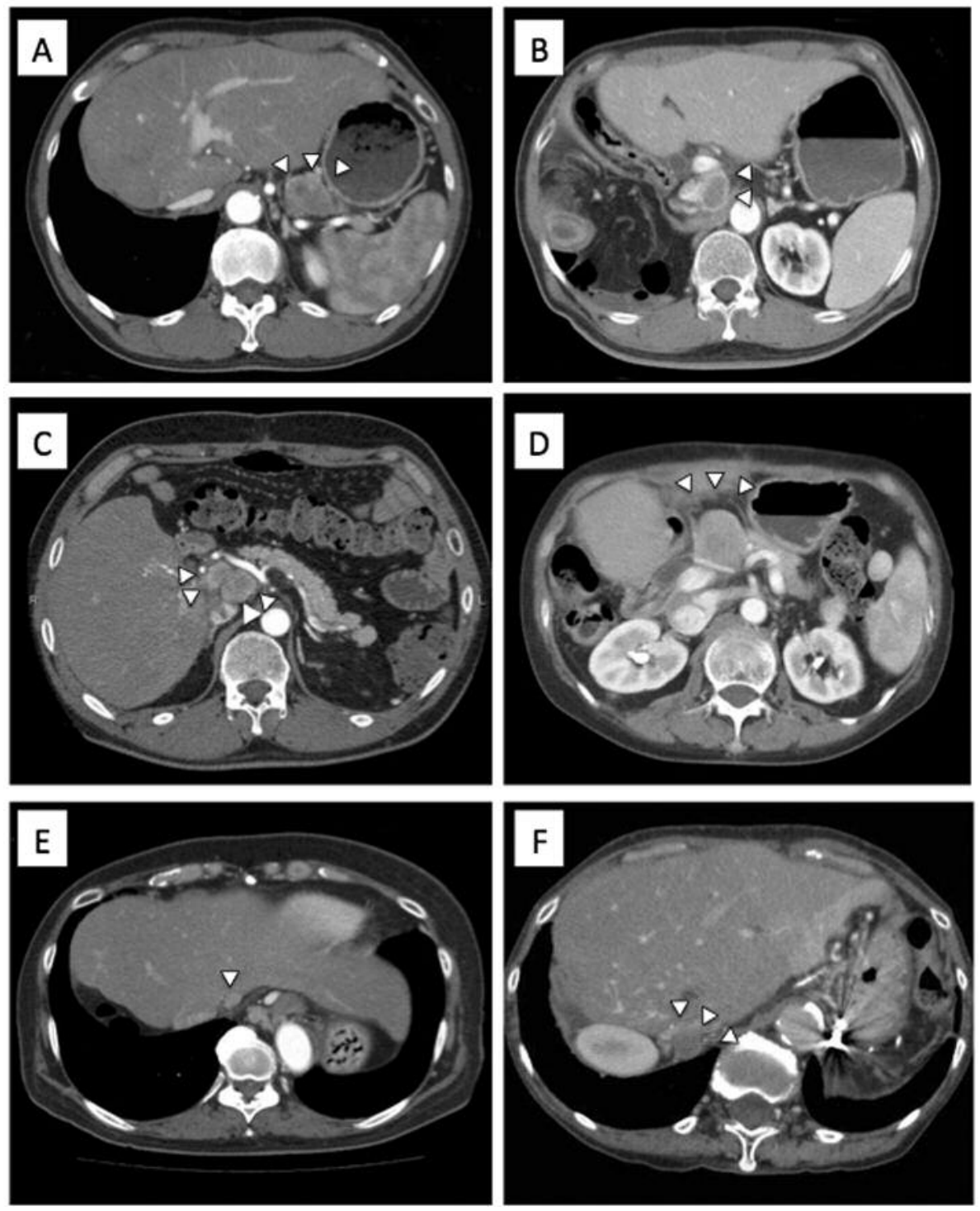

Figure 1. Lymph node $(L N)$ metastasis after living donor liver transplantation in patient 1 at the gastric $L N(A)$, patient 2 at the vena cava $L N(B)$, patients $3(C)$ and $4(D)$ at the hepatic artery $L N$, and patients $5(E)$ and $6(F)$ at the phrenic $L N$.

LNs (Figure 1, Table I). Only one patient received a right lobe graft, the others had left lobe grafts. In terms of primary HCC, the initial two patients (patients 1 and 2) were outside the Milan criteria and others were within the criteria. Poorly differentiated components were observed in two patients patients 3 and 6) by microscopic examination of the explanted liver. The mean time from LDLT to LN recurrence was $2.0 \pm 1.3$ years. The mean size of the recurrent tumor was $2.4 \pm 0.8 \mathrm{~cm}$ and all tumors were solitary except those in patient 3 . The locations of the recurrences were the phrenic $(n=2)$, common hepatic artery (CHA) $(n=2)$, inferior vena cava (IVC) $(n=1)$ and gastric $(n=1)$ LNs.
Treatments were surgery alone in three patients, surgery followed by chemoradiation in one, radiation followed by chemotherapy in one, and chemotherapy, radiation and sorafenib in one (Table I).

Patient 1 initially underwent laparotomy and surgical resection for $\mathrm{HCC}$ recurrence in a gastric $\mathrm{LN}$ at the lesser curvature (Figure 1A), 4.9 years after LDLT. Three months after the LN removal, he developed two 3-cm HCC recurrences at the root of the middle hepatic vein in the transplanted liver, and received chemotherapy comprising 5-fluorouracil (500 mg/day) and cisplatin ( $5 \mathrm{mg} /$ day) with local radiation therapy (30 Gy). However, his disease 
Table I. Six cases with lymph node (LN) metastasis after living donor liver transplantation (LDLT) for hepatocellular carcinoma (HCC).

\begin{tabular}{|c|c|c|c|c|c|c|}
\hline Case & 1 & 2 & 3 & 4 & 5 & 6 \\
\hline Age (years), gender & $56, \mathrm{M}$ & $61, \mathrm{M}$ & 46, M & $58, \mathrm{~F}$ & $62, \mathrm{~F}$ & 68. F \\
\hline Liver disease & Hepatitis C & Hepatitis C & Hepatitis B & Hepatitis C & Hepatitis C & Hepatitis C \\
\hline LDLT graft type & Left lobe & Left lobe & Right lobe & Left lobe & Left lobe & Left lobe \\
\hline Primary HCC & $3.0 \mathrm{~cm}, \mathrm{n}=4$ & $1.5 \mathrm{~cm}, \mathrm{n}=8$ & $2.4 \mathrm{~cm}, \mathrm{n}=1$ & $1.0 \mathrm{~cm}, \mathrm{n}=1$ & $1.0 \mathrm{~cm}, \mathrm{n}=1$ & $1.0 \mathrm{~cm}, \mathrm{n}=2$ \\
\hline \multicolumn{7}{|l|}{ Pathological findings } \\
\hline Size, number & $2.3 \mathrm{~cm}, \mathrm{n}=6$ & $5.0 \mathrm{~cm}, \mathrm{n}=8$ & $6.6 \mathrm{~cm}, \mathrm{n}=1$ & $3.2 \mathrm{~cm}, \mathrm{n}=5$ & $2.1 \mathrm{~cm}, \mathrm{n}=20$ & $1.2 \mathrm{~cm}, \mathrm{n}=2$ \\
\hline Differentiation & Moderate & Moderate & Poor & Well & Poor & Moderate \\
\hline Vascular invasion & No & No & Yes & No & No & No \\
\hline \multicolumn{7}{|l|}{ Recurrent HCC } \\
\hline Years from LDLT & 4.9 & 0.9 & 0.4 & 1.1 & 1.6 & 3.1 \\
\hline LN, location & Gastric & IVC & $\mathrm{CHA}$ & $\mathrm{CHA}$ & Phrenic & Phrenic \\
\hline Size & $3.4 \mathrm{~cm}$ & $2.4 \mathrm{~cm}$ & $2.7 \mathrm{~cm}$ & $3.6 \mathrm{~cm}$ & $1.1 \mathrm{~cm}$ & $1.3 \mathrm{~cm}$ \\
\hline Number & 1 & 1 & 2 & 1 & 1 & 1 \\
\hline Treatment & $\begin{array}{c}\text { Surgery, } \\
\text { chemo-radiation }\end{array}$ & $\begin{array}{c}\text { Radiation } \\
\text { chemotherapy }\end{array}$ & $\begin{array}{l}\text { Chemotherapy, } \\
\text { radiation, sorafenib }\end{array}$ & Surgery & Surgery & Surgery \\
\hline Outcomes* & $\begin{array}{c}\text { Liver metastasis. } \\
\text { Dead, } 0.6 \text { years }\end{array}$ & $\begin{array}{l}\text { Lung metastasis } \\
\text { Dead, } 1.2 \text { years }\end{array}$ & $\begin{array}{l}\text { Bone metastasis } \\
\text { Dead, } 0.5 \text { years }\end{array}$ & $\begin{array}{c}\text { No recurrence } \\
\text { Alive, } 11.2 \text { years }\end{array}$ & $\begin{array}{c}\text { No recurrence } \\
\text { Alive, } 4.5 \text { years }\end{array}$ & $\begin{array}{c}\text { No recurrence } \\
\text { Alive, } 0.8 \text { years }\end{array}$ \\
\hline
\end{tabular}

M: Male; CHA, common hepatic artery; IVC, inferior vena cava. *Time measured from LDLT.

progressed systemically and he died 7 months after the initial recurrence.

Patient 2 developed $\mathrm{HCC}$ recurrence in a $\mathrm{LN}$ adjacent to the hepatic IVC (Figure 1B) and received radiation (50 Gy) resulting in progressive disease, followed by chemotherapy comprising 5-fluorouracil (250 $\mathrm{mg} /$ day) and cisplatin (5 $\mathrm{mg}$ /day). However, he had multiple lung metastases and died 1.2 years after the recurrence.

Patient 3 developed $\mathrm{HCC}$ recurrence in $\mathrm{LNs}$ at the CHA (Figure 1C). He received gemcitabine (1400 mg/body), 5fluorouracil $(250 \mathrm{mg} /$ day $)$ and cisplatin $(5 \mathrm{mg} /$ day) resulting in progressive disease, followed by radiation (50G) and sorafenib. He developed multiple bone metastases and died 6 months later.

Patient 4 developed recurrent $\mathrm{HCC}$ in a $\mathrm{LN}$ at the CHA (Figure 1D), and both patient 5 (Figure 1E) and patient 6 (Figure 1F) developed recurrence in LNs on the diaphragm. Because we recognized at that time that nonsurgical treatment does not offer sufficient outcomes, we performed surgical resection despite the fact that the surgical approach to the lesions was not expected to be easy. Nevertheless, the operative time and blood loss for patients 4,5 , and 6 were $140 \mathrm{~min}$ and $60 \mathrm{~g}, 141 \mathrm{~min}$ and $129 \mathrm{~g}$, and $144 \mathrm{~min}$ and $60 \mathrm{~g}$, respectively, with uneventful post-surgical courses. In Patient 6, the recurrent nodule was identified just behind the junction of the hepatic and cardiac IVC on the diaphragm, and we performed a thoracolaparotomy (Figure 2A) to divide and follow the diaphragm to reach the target LN safely and effectively, avoiding injury to the middle hepatic vein on the surface of the extended left lobe graft and the IVC. By placement of the surgeon's fingers behind the diaphragm and IVC to identify and hold the targeted tumor, surgical resection of the recurrent mass was safely performed (Figure 2B). The postoperative survival period for patients 4,5 , and 6 was 11.2 years, 4.5 years and 0.8 years, respectively without any signs of re-recurrence.

\section{Discussion}

Application of the Milan criteria has allowed for widespread acceptance of LT as a treatment of choice for HCC during the past two decades, and a very low recurrence rate after LT for HCC has been achieved even following the extended criteria of LT for HCC (1). On the other hand, although the management of recurrent HCC after LT has become an issue of clinical interest, as far as we are aware, no clinical trials, prospective studies, consensus or guidelines exist on this topic (1-3).

Recurrent HCC after LT is characterized by accelerated progression and frequent extrahepatic metastasis to the lung, bone, and other organs, and these characteristics are quite different from those of HCC recurrence after hepatic resection (2, 3). de'Angelis, et al. performed a systematic review of $1021 \mathrm{LT}$ recipients and found that two-thirds of the patients had extrahepatic metastasis, the median time from LT to $\mathrm{HCC}$ recurrence was 13 months, and the survival after recurrence was 13 months (2). Despite the very poor overall prognosis, recent reports have demonstrated that curative- 

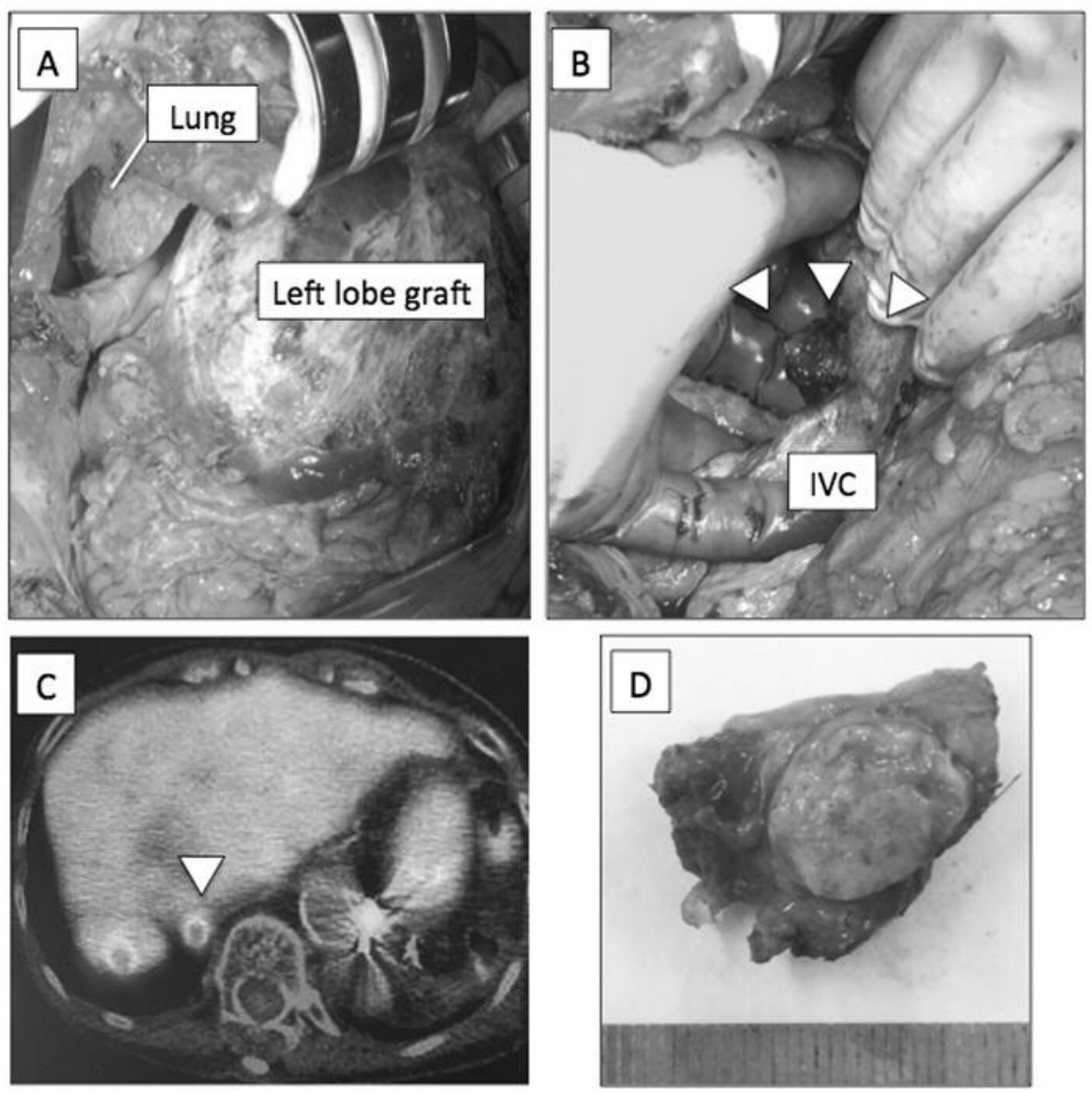

Figure 2. Thoracoabdominal approach with division of the diaphragm $(A)$ and phrenic lymph node metastasis $(B)$ just behind the vena cava in patient 6. Positive fluorodeoxyglucose-positron emission tomography $(C)$ and $(D)$ the resected specimenfrompatient 6.

intent treatments such as locoregional therapy and surgical tumor removal can increase long-term survival (5). Bodzin et al. showed that patients who received surgical treatment for HCC recurrence in the lung, liver graft, abdominal cavity, bone or brain after LT had a median survival of 27.8 months, compared with 10.6 months under non-surgical therapy and 3.6 months under best supportive care, despite significant bias in the recurrence pattern for receiving surgical resection (3).

We have described the pattern of LN metastasis of HCC after LT and the feasibility and effectiveness of surgical LN dissection in the current series. All but one (patient 3 ) of the six patients with LN metastasis had a solitary LN metastasis, and this finding is quite unique. In most cases of HCC recurrence after LT, HCC recurs secondary to circulating HCC clones that become engrafted in a hematogenous manner and grow within targeted organs; alternatively, non-detectable metastases may already be present even before LT. Because LN metastasis is not hematogenous but lymphatic, and because most of the patients with $\mathrm{LN}$ metastasis in the current series had a solitary lesion, we consider that our patients had non-detectable perihepatic local metastasis within the lymphatic defense system at the time of LT.

The feasibility of a surgical approach for the removal of perihepatic LNs was unexpectedly acceptable with an operative time of only a few hours and blood loss of $<100 \mathrm{~g}$. This is because the tissue conditions had improved since the first few months after LT, at which time they were fragile, edematous and bloody. Thus, it was possible to very safely approach LN metastases in very surgically challenging locations, as in patient 6 (just behind the IVC on the diaphragm). In patient 2, although the peri-IVC LN was surgically approachable, we were unable to evaluate the lesion as being approachable at that time point because of our lack of experience. Nevertheless, multiple LN recurrences, as in patient 3, or multiple distant metastases from LNs, such as in patient 1 and 2, are still difficult to treat. Previous reports have shown that systemic chemotherapy using 5-fluorouracil or cisplatin has very limited efficacy in controlling HCC recurrence $(2,3)$. Only sorafenib has the potential to stabilize the disease, however complete responses are very limited $(2,3)$. 
In summary, LN metastasis after LT for HCC presents as a solitary lesion in the majority of patients, and surgical resection is the only feasible and potentially curative treatment.

\section{Financial Support}

This study was supported in part by a grant-in-aid for Scientific Research (16fk0210303h0003) from the Ministry of Health, Labour and Welfare of Japan.

\section{Disclosure}

The Authors have no conflicts of interest to report. The article was not prepared or funded by a commercial organization.

\section{References}

1 Mazzaferro V, Llovet JM, Miceli R, Bhoori S, Schiavo M, Mariani L, Camerini T, Roayaie S, Schwartz ME, Grazi GL, Adam R, Neuhaus P, Salizzoni M, Bruix J, Forner A, De Carlis L, Cillo U, Burroughs AK, Troisi R, Rossi M, Gerunda GE, Lerut J, Belghiti J, Boin I, Gugenheim J, Rochling F, Van Hoek B, Majno P; Metroticket Investigator Study Group: Predicting survival after liver transplantation in patients with hepatocellular carcinoma beyond the Milan criteria: a retrospective, exploratory analysis. Lancet Oncol 10: 35-43, 2009.
2 de' Angelis N, Landi F, Carra MC and Azoulay D: Managements of recurrent hepatocellular carcinoma after liver transplantation: A systematic review. World J Gastroenterol 21: 11185-11198, 2015.

3 Bodzin AS, Lunsford KE, Markovic D, Harlander-Locke MP, Busuttil RW and Agopian VG: Predicting mortality in patients developing recurrent hepatocellular carcinoma after liver transplantation: impact of treatment modality and recurrence characteristics. Ann Surg, 2016. doi: 10.1097/SLA.000000 0000001894. [Epub ahead of print]

4 Ikegami T, Shirabe K, Soejima Y, Yoshizumi T, Uchiyama H, Yamashita Y, Harimoto N, Toshima T, Yoshiya S, Ikeda T and Maehara Y: Strategies for successful left-lobe living donor liver transplantation in 250 consecutive adult cases in a single center. J Am Coll Surg 216: 353-362, 2013.

5 Sapisochin G, Goldaracena N, Astete S, Laurence JM, Davidson D, Rafael E, Castells L, Sandroussi C, Bilbao I, Dopazo C, Grant DR, Lázaro JL, Caralt M, Ghanekar A, McGilvray ID, Lilly L, Cattral MS, Selzner M, Charco R and Greig PD: Benefit of treating hepatocellular carcinoma recurrence after liver transplantation and analysis of prognostic factors for survival in a large Euro-American series. Ann Surg Oncol 22: 2286-2294, 2015.

Received November 14, 2016

Revised January 26, 2017

Accepted January 27, 2017 